\title{
Mayel Lyang Embodied: "Tradition" and Contemporary Lepcha Textiles
}

\author{
SarahFaulkner \\ K. R. Rama Mohan
}

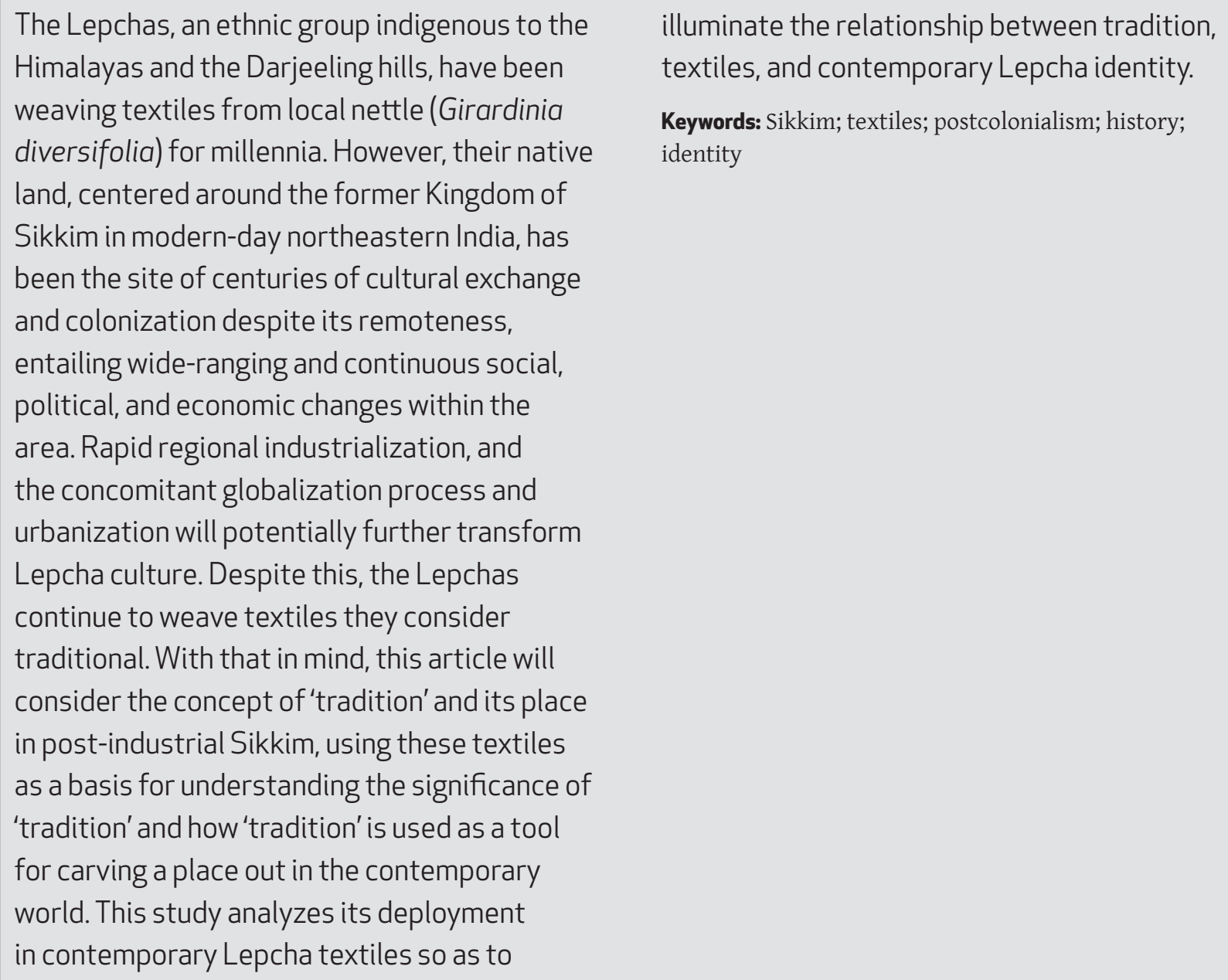

The Lepchas, an ethnic group indigenous to the Himalayas and the Darjeeling hills, have been weaving textiles from local nettle (Girardinia diversifolia) for millennia. However, their native land, centered around the former Kingdom of Sikkim in modern-day northeastern India, has been the site of centuries of cultural exchange and colonization despite its remoteness, entailing wide-ranging and continuous social, political, and economic changes within the area. Rapid regional industrialization, and the concomitant globalization process and urbanization will potentially further transform Lepcha culture. Despite this, the Lepchas continue to weave textiles they consider traditional. With that in mind, this article will consider the concept of 'tradition' and its place in post-industrial Sikkim, using these textiles as a basis for understanding the significance of 'tradition' and how 'tradition' is used as a tool for carving a place out in the contemporary world. This study analyzes its deployment in contemporary Lepcha textiles so as to

illuminate the relationship between tradition, textiles, and contemporary Lepcha identity.

Keywords: Sikkim; textiles; postcolonialism; history; identity 


\section{Introduction}

India's state of Sikkim in the southern hills of the Himalayas, though remote, has been animated with cultural exchange throughout its history. Interactions between Sikkim's native communities and outside forces have been the impetus for innumerable changes. The Lepchas, ${ }^{1}$ an ethnic group indigenous to the land in and around Sikkim, have experienced and acclimated to the effects of these phenomena for centuries. These phenomena, primarily the colonial rule of Sikkim by the Tibetan Bhutias and later the British, have been associated with the gradual transformation of Lepcha culture (Bentley 2007). Sikkim's increasing industrialization and urbanization can potentially further affect Lepcha culture. Lepchas now constitute less than a quarter of Sikkim's population. When discussing the Lepchas' dwindling numbers and the community's traditional culture, Lepcha and Western writers alike have described the Lepchas as a "vanishing tribe" (Foning 1987, Gorer [1938]2014, Bentley 2007: 59). In part because of the perceived threat of cultural loss, a movement has emerged within the community to conserve Lepcha culture and adapt its 'traditions' to the contemporary world. 'Tradition' has become a tool to carve out the Lepchas' place, so to speak, in a space where they are increasingly marginalized. The community's textiles are among the components of Lepcha culture being preserved in a larger effort to retain Lepcha cultural identity, and thus, may be studied in order to understand the place of tradition in Lepcha society and its significance in the contemporary sociopolitical environment and economy. This study analyzes contemporary Lepcha textiles so as to illuminate the relationship between tradition, textiles, and contemporary Lepcha identity. ${ }^{2}$

What, though, is tradition? Numerous scholars have engaged with this concept and its significance in postcolonial societies, and their work may be drawn on in order to form the theoretical framework for considering tradition and its place in contemporary Lepcha society. Generally, tradition is a cultural process that involves the transmission of customs and conventions from generation to generation. Tradition can be seen as consequentially somewhat of an heirloom, whether it be tangible or intangible, a link from the present to the past. In his article, "What is Tradition?", Nelson Graburn establishes a useful framework for understanding how tradition has been conventionally conceptualized. In this conceptualization, "tradition" is usually presented as the diametric opposite of "innovation" and change due to its links to the past (Graburn, 2001: 6); tradition is a "name given to those cultural features which, in situations of change, were to be continued to be handed on, thought about, preserved and not lost" (ibid). This dichotomy, where tradition and innovation are set at opposite poles, effectively cleaves a united history in two along the same lines-there is the 'isolated,' 'backwards' past from which traditions are said to originate from and then there is the period after colonists arrived with 'modernity' and 'innovation.' In this way, colonial societies are also cleaved-there are the passive, static, or at best 'pure,' colonized societies and there are active colonizers who enact change and promote innovation. This thinking denies communities like the Lepchas agency in actively participating in their own history and presents tradition as a variable outside of this history, an element inextricably linked to both the 'untouched' and 'untouchable' fantastical, pre-colonial past. Traditions like the production of textiles, which has manifested tangible products throughout time, challenge this dichotomy as handicrafts are inherently linked to technological and material innovations and, as commodities, economic and cultural exchange. Yet, 'tradition' and progress are often seen as mutually exclusive in this perceived dichotomy, and 'tradition' is often presented as a trapping, unconquered as it is 'unchanged.' However, this is not the reality. As, Graburn articulates, tradition is and has been an ongoing cultural process that is continuously developed throughout time, even after "modernization" (ibid: 8). The intricacies of the continuous process of tradition development and even the invention of tradition in recent times for multifarious purposes is further expanded upon by Geertz (1973), Hobsbawm and Ranger (1983), and Asad (2009). Furthermore, "[e]ven these new, historically created phenomena are often quickly assumed to be age-old or timeless, because people want them to be so and because the customs become invested with authority that is difficult to challenge" (Graburn 2001: 8). These ongoing processes challenge not only the imagined dichotomy of tradition and modernity, but also the conception of tradition as a whole. 'Tradition,' as a monolithic concept (especially when set conceptually opposite to modernity), is problematic as it denies this continual process and, by extension, the active participation of colonized communities in their own history of cultural exchange and cultural transformation. Indeed, traditions provide a link to the past, but this past was never insulated from cultural exchange and cultural transformation, yet, the monolithic conception of tradition, and by extension cultural identity development in colonized societies, is inaccurately conceived of as limited to a time isolated from the progress defined by their colonizers, when in reality, it is constituted by modernity and does not necessarily indicate backwardness.

On the other hand, tradition is also a reservoir of strength as it is "a source of historically defined identity, and a 
source of a sense of safety, specialness, or difference" (ibid: 9). Tradition as a reservoir of cultural identity, a concept described by Horner (1990), is a means of understanding the association between tradition, Lepcha textiles, and Lepcha cultural identity within the present study. This study will consider how traditional Lepcha textiles, as they are considered both carriers of cultural history and visible reservoirs of Lepcha cultural identity, have recently been deployed in order to lay claim to a place for Lepcha identity in the contemporary world in response to the perceived threat of cultural loss.

\section{'Tradition,' Transformations, and Textiles}

Lepcha traditions today are strongly associated with their shared history, which began, according to their oral history, in Mayel Lyang, which roughly translates to 'hidden land.' This ancestral land is based around Kanchenjunga's Pandim peak, where the Lepchas' creator god formed the community's progenitors from the summit's snow (Subba 2009: 382), and encompasses modern-day Sikkim and the Darjeeling hills. Contemporary anthropologists largely accept the Lepchas as the earliest settlers of the land between the western Rangit and eastern Teesta rivers in the rolling hills and lofty peaks that surround Mount Kanchenjunga's eastern and southern flanks (Gorer [1938]2014: 35, Choudhury 2006: 24). Modern borders divide what is known as the Lepchas' indigenous territory between Sikkim and the Darjeeling district of West Bengal, though the present Lepcha diaspora spreads into eastern Nepal, southwestern Bhutan, and parts of Tibet (Lepcha 2016: 1, Subba 2008b: 249). This is where the Lepchas have remained for potentially millennia (Mullard 2011: 5). Kanchenjunga and its surroundings can thus be considered Lepcha culture's birthplace and primary influencer.

Lepchas reportedly wore animal pelts for some time, but textiles woven from Himalayan nettle (Girardinia diversifolia or Girardinia palmata) eventually superseded pelts as clothing (Sarkar 1995: 70, Subba 2008b: 224, Pradhan and Badola 2008: 12). Nettle fabric presents several advantages over fur when considering the Lepchas' homeland. Pelts are cumbersome, interfering with the mobility required to navigate Sikkim's environment, and may have provided more heat than was comfortable or necessary. Nettle fabric, however, is durable and light-weight (Rastogi and Srivastava 2018: 281-282). Natural air accrual within nettle filaments' hollow cores additionally provides organic insulation that can be decreased by twining the fibers to obstruct the cores before weaving, enabling Lepchas to produce nettle clothing adapted for a range of temperatures (ibid: 282). Additionally, because nettle is perennial and fairly abundant throughout Sikkim and its environs, it was available wherever the Lepchas traveled in the region (ibid). Nettle textiles thus form the basis of Lepchas' weaving traditions. These textiles accordingly indicate and reflect the Lepchas origins in the area. This material was also reportedly historically used by some surrounding communities (including the Bhutanese, Nepalis, and Limboos), who inhabited similar geographical regions and had access to the same materials. According to Lepcha oral history, weavers reportedly produced unadorned nettle textiles on handmade back-strap looms (also known as loin looms). However, both Lepchas and Limboos were allegedly also weaving with cotton and using vegetable dyes to color their woven goods at some point before the seventeenth century (Subba 2008b: 140-141). Oral histories describe these original textiles as being nettle girdles (Lepcha: nyemrek), cross-body bags (tangyip), and large cloths used for both attire and practical functions (dum-prá for men's garments and dum-vun for women's garments). While historical examples of these tools and products are no longer extant, back-strap looms and textiles of these types are still being used and made, respectively. Garments, furthermore, seem to still be worn in their 'historically correct' manners. Practice and oral transmission of knowledge is doubtlessly the primarily force behind the transmission of these traditions. Thus, contemporary textiles that are derived from generationally transferred traditions are representative of the oral history that they were learned from. These oral histories teach of the textiles' roots in the community's past and in their homeland before the intervening forces of colonialism.

The Lepchas were not, however, insulated from cultural change and cultural exchange here even before the advent of colonialism, though their connection to their homeland of Sikkim is extremely significant in terms of their cultural identity. The community reportedly shared what is now modern-day Sikkim with the Limboos and Mangars, who each ruled autonomous domains within the area. Tibetans began migrating to Sikkim sometime after the seventh century (Subba 2008b: xix, 9-10; Singh 2008: 97-98, Subba 2008b: 347). Among these migrants were members of the Bhutia tribe (Chakrabarti 2012: 2), whose descendants later became the leaders of the Chogyal monarchy, which was established in c.1642 CE (Subba 2008b: 14). Their domain, the Kingdom of Sikkim, was founded by the Lho-MehnTsong-Sum treaty, which certified the Lepcha, Limboo, and Bhutia as Sikkim's original tribes, indicating the tribes' acceptance of Chogyal sovereignty and granting the Chogyals dominion over the tribes' land resources, signifying that the Lepchas were only tenants of their homeland, which was declared the Chogyals' rightful property (ibid: 22, Shulka 1976: 14, Chakrabarti 2012: 2). 
This marked the beginning of a history of colonialism and the marginalization of the Lepchas in their own claimed homeland.

The monarchy's formation also entailed interaction with political entities surrounding the kingdom, including Nepal, Tibet, Bhutan, and China. Sikkim's borders were constantly reshaped throughout the eighteenth century as these countries took control of Sikkimese land following confrontations with the Chogyals (Subba 2008a: 114). Sikkim's politicization eventually led to contact with the British. Sikkim effectively became a British protectorate in 1861, abolishing the Chogyals' liberty to take direct political action and fully opening Sikkim to trade with British India in the process (Chakrabarti 2012: 3). Subsequent British-led infrastructure and agricultural developments in Sikkim and Darjeeling displaced local Lepcha inhabitants (Das 2009: 92). Not only did this transform their environment physically, but it also doubtlessly led to internal and external transformations of their sociopolitical, economic, and cultural environments as well.

In terms of textiles, oral histories convey a number of transformations to Lepcha dress culture. The Chogyal monarchy's establishment introduced some of the first conditions to provoke syncretism. The Lepchas continued to weave their own textiles, but they also began wearing traditional Tibetan/Bhutian clothing in addition to traditional Lepcha clothing (Gorer [1938] 2014: 52-53, Subba 1985: 65). These Tibetan/Bhutian clothing items included silk male and female robes as well as cotton and silk male and female undershirts and trousers. By the twentieth century, some Lepcha men also reportedly began wearing purple, blue, and red long-sleeved, buttoned overcoats similar to those worn by Tibetan Buddhist lamas (Gorer [1938] 2014: 53). This reported change in fashion marked an interaction between cultures-Lepchas, Bhutian, and Tibetan, likely as the result of both cultural exchange and an open trade network between Tibet and Sikkim (Keshav 2014: 107-143). After the arrival of the British, an even higher magnitude textiles and materials were available in Sikkim. Cotton and wool were notably traded with both Tibet and the British (ibid, Palace Archives of Sikkim 1905-1910). Simultaneously, British, or otherwise foreign, companies began employing Lepchas to weave textiles other than their own traditional crafts. Cotton production and silk weaving were commonplace throughout Sikkim at this time (Finley et al. 1913: 215). Cotton textiles concurrently became more popular amongst the Lepchas (Wardle 1886: 176). The British also encouraged Nepali immigration to Sikkim, drastically transforming Sikkimese demographics (Choedon 1995: 74). Today, the Lepchas constitute approximately less than ten percent of Sikkim's total population and the Nepalis constitute about three-quarters of Sikkim's population (Bhasin 2011: 42). Nepalis brought their own dress culture with them as well as popularized settled farming in Sikkim, provoking deforestation exacerbated by infrastructure development (Gurung 2017: 44). The Lepchas still supported themselves through hunting, gathering, and shifting cultivation until c. 1880 , but eventually virtually abandoned these activities for settled cultivation, which became their primary source of food and profit after the nineteenth century (Subba 2008a: 115; Subba 1985: 65).

Eventually, the Chogyals recovered some autonomy near the end of British occupation in the area. Sikkim did not join India after the British Raj's dissolution in 1947, but it did become an Indian protectorate in 1950 (Subba 2008b: xxv). India annexed Sikkim in 1975, dissolving the Chogyal monarchy. The annexation has encouraged further urbanization and industrialization, as well as a greater influx of mainland Indian citizens into Sikkim. Now, Sikkim has entered the global scenario as well, as Sikkim has become a tourism hub for national and international travelers.

One of the many draws of Sikkim is the Lepchas themselves, who are posed by their grass-root organizations and government institutions alike as an 'authentic' indigenous community, 'insulated' from the effects of cultural exchange within their villages, which may be visited by travelers. As traditions of this community and visible reservoirs of their cultural identity, textiles are significant in these conditions. They are tied up in the concept of tradition as something 'untouched' by history, a vessel of the seemingly bucolic and insulated past in Mayel Lyang, their production practices passed generation to generation

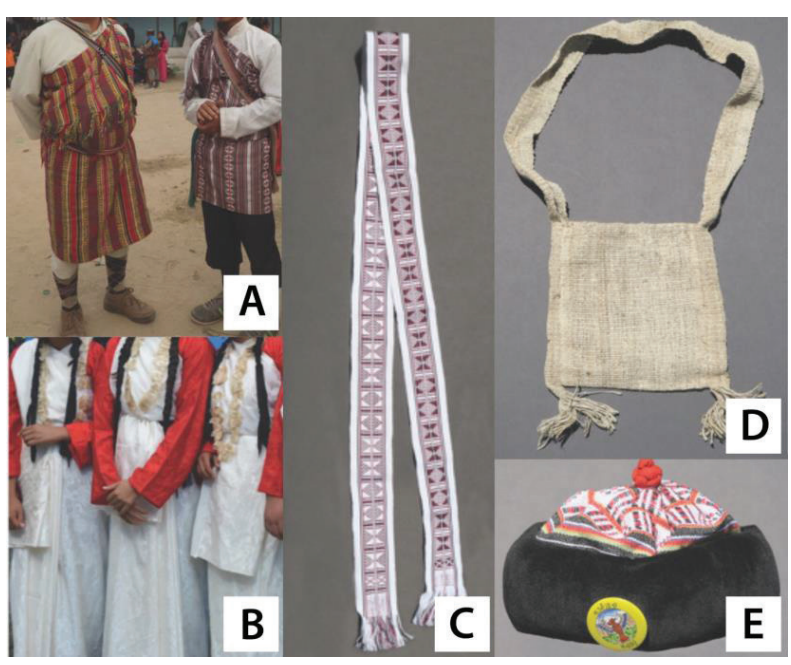

Figure 1: Contemporary "Traditional" Lepcha Textiles A: male garment (dum-prá) B: female garment (dum-vun) C: girdle (nyemrek) D: nettle cross-body bag (tangyip) E: round cap (anok thyaak-tuk) 
within the Lepcha community. Nettle textiles in historical forms, in particular, ground the Lepchas in their past and, more significantly, their homeland.

Current efforts to preserve the Lepcha culture prior to post-industrial interaction, such as textiles, are supported by a number of organizations. These efforts rely on the passing of historical methods of construction among generations, while being sustained by grass-root associations and government-based organizations' effort to document Lepcha's heritage. Many of these groups have emerged in the past century intrigued by the rapid sociopolitical, economic, and cultural changes in Lepcha communities and in response to the perceived threat of loss of cultural identity both due to these changes and to the Lepchas' dwindling population. Dress culture, as a visible component of cultural identity, is a visual way of highlighting the presence and components of Lepcha cultural identity. These associations host or are involved in events celebrating Lepcha traditions, including Lepcha textiles, which are sold and exhibited at these gatherings. Historical garments, though not worn in many Lepchas' daily lives today, are also conventionally worn at these events, allowing these clothes to be not only historical articles but also active components of contemporary Lepcha culture. Lepcha festivals occur nearly monthly across Sikkim and areas in surrounding countries (e.g. Nepal and Bhutan) and states (e.g. West Bengal) with notable Lepcha populations.

In 1957, the reigning Chogyal established the Technical Institute for Training and Production of Traditional Arts and Crafts (also known as the Government Institute of Cottage Industry) to "preserve and revive the languishing ethnic [t]raditional [a]rts and crafts of the state," generate income, and provide employment by training aspiring artisans (Subba 2008b: xxvi, Directorate of Handicrafts and Handloom, Government of Sikkim 2012). Since opening, the Institute has taught artisans to weave Lepcha textiles on back-strap looms. Trainees also initially learned to dye yarn. Additionally, American designers were invited to Sikkim to promote textile design diversification. Thus, while there are implements in place to ensure the preservation of former traditions in an increasingly inter-culturally diverse Sikkim, efforts have also been made to bolster this survival through the adoption of new techniques and designs. These not only open up the textile market to new consumers but also encourage innovations that will continue to allow Lepcha textiles to serve as living and evolving components of the community's culture. The Technical Institute for Training and Production of Traditional Arts and Crafts, now the Directorate of Handicrafts and Handloom (DHH), continues to contribute to the survival of Lepcha textiles' traditions by teaching aspiring artisans to weave Lepcha textiles using historical methods through the usage of back-strap looms. There are now seventeen DHH training centers across Sikkim that teach Lepcha weaving; these have trained approximately 2,000 weavers (Directorate of Handicrafts and Handloom, Government of Sikkim 2016). The DHH also teaches marketing skills and, since 2003 , has sold textiles produced by its artisans at affiliated sales emporiums inside and outside the state (ibid).

Conservation has not, however, inhibited Lepcha textiles' formal and decorative evolutions. Surveying contemporary Lepcha textiles identifies how current crafts now diverge from Lepcha oral history's description of their historical textiles as unadorned nettle robes, belts, and bags (see Fig. 1). New traditions have even been developed, as round caps (anok thyaak-tuk) have been adopted into the traditional dress culture by uniting the form with Lepcha mythohistory, though these caps are not described in oral histories as being historical textiles. ${ }^{3}$ This is in some ways a case of the "invention of tradition" described by Hobsbawm and Ranger (1983), yet the significant takeaway from the adoption of the anok thyaak-tuk is that tradition is oriented towards the conception of the past, as articulated by Asad (Asad, 2009: 21). In this way, it can be seen that what is considered 'traditional' in Lepcha history is that which connects them to their conception of the past. Contemporary Lepcha textiles of all kinds also employ a range of new forms, decorations, materials, and production methods that set them apart from their reported historical counterparts, yet they are still considered traditional by the Lepcha community. This suggests the continual innovation of traditions throughout time and, not only that, the contradictory notion of tradition as a diametric opposite to modernization as a whole.

These adaptations to Lepcha textiles bespeak the transforming conditions of their environment as their acceptance as traditional despite these adaptations challenges the rigidity of what 'tradition' is. For example, weaving nettle fabric is laborious and time-intensive. Deforestation has also reduced the nettle population. Consequently, nettle textiles are almost ten times more expensive than other textiles. The DHH additionally does not teach nettle weaving and independent artisans generally weave with more accessible materials. Thus, 'historically correct' textiles are often woven in more accessible materials (i.e. wool, cotton, silk, synthetic fibers) on faster looms (i.e. frame looms and power looms), but are still considered traditional. Moreover, textiles are decorated with designs and colors that have some meaning relevant to Lepcha cultural identity, which 
allows for product diversity and market appeal, but are still considered traditional, even as the historical textiles were reportedly unadorned. Objects like waistcoats, file covers, laptop cases, and non-traditional bags (e.g. bangle bags, drawstring bags, and wallets) are adorned with what are considered Lepcha decorations or otherwise visually relate to established Lepcha crafts and thus still relate to Lepcha tradition. Contemporary motifs (and even colors) that are accepted as 'traditional' evoke the Lepchas' oral history of their hunting-and-gathering lifestyle before industrialization and the community's historical relationship with nature by capturing their homeland's wildlife (i.e. bamboo, butterflies, insects, and ferns). These motifs and colors serve as a link to the community's shared history of their past before colonization, even as they were mostly conceived or at least imbued with meaning in a time after colonization. On the other hand, crafts are typically machine-made and tourist-oriented. Therefore, they are embodiments of the contemporary age-with its technologies as well as increased globalization and cultural exchange. Yet, even as this may be seen as a deviation from the past, creating new forms according to new market demands allows for the preservation, documentation, and dissemination of Lepcha history to an even larger audience. The deployment of representative decorations appears to allow these textiles to still serve as visible reservoirs of Lepcha identity and history, no matter what form they take, and thus enable the textiles to be considered traditional. The acceptance of these "historically incorrect' textiles as traditional indicates that the significance of these textiles traditions are their ability to elucidate the conception of the Lepchas' past and cultural identity. Moreover, it confirms Asad's conjecture that "for even where traditional practices appear to the anthropologist to be imitative of what has gone before, it will be the practitioners' conceptions of what is apt performance, and of how the past is related to present practices, that will be crucial for tradition, not the apparent repetition of an old form" (Asad 2009: 21). This allows for active integration of Lepcha cultural identity, through textiles, with the contemporary world.

However, new weavers are learning to weave with nettle, and nettle belts and bags are easier to find now than in the past century. Aspiring weavers still commonly learn to produce the crafts on back-strap looms. The interplay of 'tradition' and contemporaneous conditions is evident in these products and practices-even as Lepcha dress culture has become more global, their weaving practices have become more industrialized, and their market has expanded, there is still a parallel line of adherence to what is considered a 'pure' tradition within textile production and usage that has become increasingly significant within the Lepcha community. However, this interest in tradition, the past, and the preservation of the two within Lepcha cultural identity is in itself affected by contemporary conditions. The two do not exist separately. For example, the overall stance of the Lepcha grass-roots organization indicates that the primary driving force behind the recent return to nettle textiles within the Lepcha community is to preserve elements of their historical culture in the face of centuries of cultural exchange, yet there has also been an upsurge in interest in the nettle textile market by non-Lepchas. Tourists, corporate offices, and academic institutions have all expressed increasing interest in nettle textiles. 'Tradition' is as much a means of identity preservation as it is a marketable commodity in contemporary society.

There is, in fact, a marked fascination with 'tradition' throughout Sikkim. Since India's independence, Scheduled Tribes were given 'Reservation' status, which guarantees political representation through India's constitution. In order to qualify for such a status, indigeneity must be proven. This has doubtlessly provoked many Sikkimese communities to be pre-occupied with 'tradition' as well as "isolation from the mainstream" in order to qualify for the benefits associated with being considered an "indigenous tribe" (Vandenhelsken 2021: 214). The Lepchas have been considered an indigenous tribe by the central government since 1978, a mere three years after the annexation of Sikkim by India (ibid: 219). As a result, they do not have to prove their 'authenticity,' yet, the current political environment is one that attaches great value to 'tradition.' This general interest is burgeoned by tourists who hope to see 'authentic' and 'primitive' cultures on their visits to Sikkim. For example, Dzongu, a Lepcha village, is posed by Sikkim as one of the last "primitive villages" in their marketing campaigns and the pan-Lepcha spiritual hub by the Lepchas themselves. (ibid: 226) This interest in the 'authentic' and 'primitive' is felt nationally, even outside of Sikkim, as Lepcha weavers stand to profit from the sales of nettle textiles, at annual handloom fairs in New Dehli.

These political and economic issues are a backdrop to a much larger source of concern within the Lepcha tribe, though. Showcasing 'traditional' forms is an element of Lepcha community preservation by and large, born from the perceived threat of identity erasure. Colonization of Lepcha lands and a dwindling population (especially compared with the growing number of people from other communities inhabiting Sikkim) have prompted the Lepchas to prioritize and deploy 'tradition' in response to these anxieties. Lepcha textiles are currently used as a powerful symbolic representation of their culture and identity. Aspects of historical Lepcha weaving still maintained include the usage of nettle yarn, the back-strap 
loom weaving method, and recognized traditional forms (i.e. unadorned dum-prá, nyemrek, and tangyip). These elements constitute a foundation for contemporary Lepcha textiles as well as evoke the Lepchas' connection with their native environment and their oral history of a historic nomadic, hunting-and-gathering lifestyle. More specifically, dum-prá, without undergarments, allow for the mobility that the Lepchas required to traverse their homeland's terrain. Tangyip's integrality to historic ensembles indicates a past of daily exploring and gathering necessities. The back-strap loom recalls when the Lepchas regularly traveled throughout the region and required looms that could be made and assembled wherever a post was available. The historical usage of Himalayan nettle fabric most clearly elucidates the Lepchas' homeland's domain and range of nomadic migration, as this nettle is native to the area in and around the Lepchas' homeland. Nettle consequently forms a thread transcending the gap between past and present, tethering contemporary Lepchas to their homeland and asserting their belonging in a place where they have been marginalized-a material answer to concerns about erasure of Lepcha culture. For this reason, unadorned nettle textiles are seemingly posed in contrast to the new mass-produced, post-industrial, dyed textiles made from other, more readily available materials due to both nettle's geographic ties to the Lepcha's homeland as well as its' association with historical textiles. Nettle textiles' association with what is considered 'traditional' Lepcha culture is one of their major draws-because the perceived threat of cultural loss within the Lepcha community causes the Lepchas to increasingly perceive the importance of preserving, adapting, and promoting 'traditional' Lepcha culture (Bentley 2007: 78). The DHH's primary directive-“to preserve and revive the languishing ethnic $[\mathrm{t}]$ raditional [a]rts and crafts of the state" (Directorate of Handicrafts and Handloom, Government of Sikkim 2012)-is telling of Lepcha textiles' perceived relationship to culture loss and cultural preservation. Lepchas are motivated to produce, purchase, wear, use, and otherwise support the continued significance of textiles in Lepcha culture-particularly those that are considered 'traditional,' like nettle textiles and others that reflect Lepcha identity. The usage of textiles for this purpose is an alternative to undertaking ethno-political activism to preserve their identity in the multi-cultural matrix of Sikkim. Lepcha marginalization is prevalent not only in the cultural sphere but also the political: they do not hold any major political power and their rates of land-holding is low since Sikkim's annexation, especially when compared with other minority ethnic groups in the state. 'Tradition' distinguishes the Lepchas' cultural identity amongst the rest, as well as providing a means for economic viability in a contemporary market that values 'tradition' as a commodity.

Yet, even with this prioritization of 'tradition,' the Lepchas have not been insulated from cultural exchange, and their 'traditional' textiles reflect that. Analysis of contemporary Lepcha textiles accordingly indicates that the crafts balance custom and change, rather than forfeiting one or the other. This relates to Lepcha cultural associations' general efforts to adapt Lepcha traditions to the modern world. Historical tangyip may be woven with synthetic teal and purple threads on a power loom. Unadorned nettle nyemrek, woven on a back-strap loom, may be worn over jeans. There are endless varieties of Lepcha textiles, but few are wholly 'traditional' or 'non-traditional.' In Lepcha textiles, there is a sliding scale of custom and change-the two qualities may be different, but they are not mutually exclusive. In fact, the two qualities often cannot be truly separated from one another now. One recalls Homi Bhaba's statement that " $[t]$ he trace of what is disavowed is not repressed but repeated as something different-a mutation, a hybrid" (Bhaba 1985: 153). This challenges both the notion of cultural purity within the sphere of Lepcha textiles-an illusion that disregards their history-as well as the notion that colonial powers may erase and 'fix' the culture of a colonized community. Instead, Lepcha textiles, with their many variations, are a testament to the ongoing processual formation of Lepcha identity throughout history.

Moreover, there appears to be a reciprocal relationship between innovation and preservation that affects not only the crafts themselves but also their place in the community and economy. For example, producing Lepcha textiles is more accessible due to current methods of production. Weavers can forego both collecting materials and preparing and dying yarn because pre-prepared yarn of various non-nettle materials and colors are more available in the markets. Power looms and cheaper materials enable weavers to make products more regularly and sell them to more people by increasing supply and lowering sale prices. Urbanization, capitalistic industrialization, and the associated tourism boom in the area have also made weaving Lepcha textiles more consistently profitable, motivating more people to professionally weave them. Increased access to materials and mass-production has made weaving a more accessible profession at the same time as it has opened the textiles to a larger market. These textiles provide a contemporary source of income for Lepchas, enabling the Lepchas to contribute to the modern economy and thus has led to the increasing participation of Lepchas in the interculturally connected global forum, which sequentially affects Lepcha textiles. Alternative 
sources of income are increasingly desirable for Lepchas to take up in the contemporary capitalist economy, and unlike crops, textiles are revenue sources generally unbound by the seasons or natural circumstances. Additionally, Lepchas who wish to connect with their community's culture are motivated to buy contemporary Lepcha textiles because they are tangible products of their historical value, rendering the textiles much more profitable than other textiles during the nearly monthly festivals that celebrate Lepcha culture. Their textile sales are thus consistently profitable, unlike other sources of income. Due to the profit associated with Lepcha textiles, members of other communities are also motivated to take up Lepcha weaving, encouraging additional cultural exchange. To do so, though, aspiring weavers must learn from senior weavers. Senior weavers inherently pass along Lepcha methods of production by teaching their students to weave Lepcha textiles on back-strap looms but are also likely prompted to recall other cultural concepts associated with Lepcha weaving. Thus, even new materials and methods of production are still infused with Lepcha history and identity-a 'trace' in Bhaba's sense of the word.

Yet, this 'trace' has been developing since long before the introduction of industrial practices. The evolution of the 'trace' found in Lepcha textiles reaches deep into Sikkim's colonial history. The interactions between Lepcha culture and the culture of others throughout this history was, moreover, always associated with trade. Trade of either ideas related to commodities or the commodities themselves between the Lepchas and others is evident in the usage of non-nettle materials popularized during both the periods of Bhutian and British colonialism. Silk, wool, and velvet are shared by Lepchas and others, including the Bhutias, various Nepali communities, various Bhutanese communities, and people inhabiting the Tibetan plateau and mainland China. Lepchas often wear their clothing with styles of tops and trousers common to the historical outfits of many of these cultures, indicating interactions between them and the Lepchas. This is especially evident in the similarities between contemporary outfits worn by Lepcha women and those worn by other communities as well as between the styles of 'non-traditional' waistcoats worn by Lepcha men and those worn by other communities.

The adoption of tago and tomoo into male outfits during these phases of history also seems to indicate their transition from hunting and gathering to settled agriculture as the result of colonial influence and economic interests. Trousers and sleeves can protect skin from contact with dense, scratchy crops and weeds, as well as sunburn from prolonged work in areas not covered by trees, which would typically shade hunting grounds. These additional garments also sacrifice some mobility required for hunting and thus are representative of the changes in Lepcha society as the community increasingly farmed, rather than relying solely on hunting and gathering.

Thus, Lepcha textiles have always formed an inextricable link between culture and economy and provide evidence of the cultural interactions embedded in both components as the result of colonial encounters. This challenges the economic-cultural binary as well as the illusion of the Lepchas' isolation from the economic sphere throughout their colonial history. Trade, rather, is situated as a practice conducted under the social frame that culture provides (Zein-Elabdin 2009: 1156). The textiles' commodity chain itself is, throughout time, a stage for the intersection of multiple cultures, with raw goods sourced from multiple locations and the output sold and spread to multiple locations. Yet, this commodity chain's reach has expanded with industrialization and burgeoning trade networks fueled by post-industrial infrastructure developments and globalization. With this in mind, one may turn to the contemporary entanglement of Lepcha textile trade with broader cultural concerns.

The dual forces of industrialization and the commodity chain opening up from the local to a national sphere have prompted the production of textiles of a different, more easily manufactured quality on a large scale. This has provided a tool for the Lepchas to showcase their textiles to a wider market and participate within the national, post-industrial economy even as there is a permanent parallel of resistance to change within the Lepcha community. Contemporary Lepcha textiles employ a greater variety of forms and decorations than before, and these forms, colors, and designs may appeal to certain people more than former variants-a testament to how culture and economy are inextricably linked and mutually informative. As aforementioned, the 'traditional' motifs with community-accepted, historically-rooted meanings are also being used in new and diverse ways as well due to aforementioned political concerns. As these motifs are linked to the tribes' past by visually evoking the Lepchas' hunting and gathering heritage and their historical familiar relationship with nature, the designs have become vessels of Lepcha identity that can display historical Lepcha culture today where it may otherwise not be visible-a function that former customary Lepcha textile forms cannot always fulfill. More specifically, these motifs can adorn products exclusive to the contemporary world, like laptop bags, and contemporary products that can be easily worn and transported, like wallets and vests. Lepcha-identified motifs then allow the Lepchas to 
showcase their culture even as they meet market demands by adopting new forms, new production methods, and new materials. By producing such objects, weavers are both resisting the effects of industrialization on their culture by rendering their pre-industrial past visible as well as participating in industrialization in the process of producing new forms for a post-industrial, capitalist society.

These new crafts' association with 'conventional' Lepcha and Sikkimese culture also motivates tourists to purchase the goods because the crafts can conceptually transport the owner back to their time in Sikkim or with the Lepchas in the surrounding areas. This may also motivate Lepchas not living in their community's homeland to collect the textiles. Those who have returned from abroad with Lepcha textiles can show others the mementos, which may encourage others to travel to Sikkim, potentially motivating further globalization and thus further stimulating Sikkim's economy, which advances their participation in the global scenario. The marketability of 'tradition' thus is a dual force-it allows the Lepchas to render their identity visible even as it bespeaks ever-increasing involvement in the intersections of multiple cultures via trade and the commodity chain. Effectively, it carves out Lepcha space in an environment in which they are increasingly marginalized. Moreover, once textiles are released to consumers, they begin a social life of their own that continually informs their meaning throughout time and under the influence of ever-changing transformative conditions. In other words, Lepcha textiles, though tied up in history, become their own actors in the contemporary environment, begetting even more cultural interaction throughout time (Appadurai 1988).

\section{Conclusion}

The Lepchas and their native land have undergone transformations that all but obscure the past underneath a contemporary veneer. In contemporary dress culture, this is seen most profoundly with the Lepchas' routine donning of modern, Western-style fashion, a testament not only to their years under British colonial rule but also the increasing process of historical cultural interaction set upon Lepchas' homeland. Cultural interactions beginning prior to contemporary times are also evident in Lepchas' widespread consumption of non-Lepcha fashion, including sarīs and Bhutian, Bhutanese, Tibetan, and Nepali traditional clothing. Within Lepcha textiles, the integration of outside-originating textile properties exhibits the impact of centuries of cultural exchange on the community while the adoption of new forms, manufacturing methods, and materials exhibit the present era's effects on textiles.
Sarah Faulkner is an Asian art historian. She earned her Bachelor of Arts degree, summa cum laude, in Art History and Sociology from the University of Alabama at Birmingham and holds a Masters of Arts in Art History from Columbia University. She studies the reinterpretation of history through art and the intersection of politics and painting in seventeenth century Japan.

K. R. Rama Mohan is an Associate Professor, Department of Anthropology, Sikkim University, India. Some of his research interests include developmental aspects of ethnic communities in Sikkim Himalayas.

Special thanks to Mr. Tom Tshering Lepcha, Ms. Rongynyoo Lepcha, and all the respondents for this research study.

However, Lepcha textiles' association with tradition continues to be emphasized even in spite of the transformations to textiles and their productions, in part a response to the perceived threat of cultural identity loss as a result of centuries of colonization, marginalization, and population reduction. Due to their dwindling numerical strength in Sikkim, lack of political representation, marginal economic status, and the upsurge of other ethnic communities who are relatively in superior sociopolitical positions, Lepchas perceive themselves as less powerful and moreover, less visible and less present in their homeland. This has paved way to their mobilizing more towards the preservation and revival of Lepcha textiles and other visible objects imbued with associations with the Lepcha cultural identity. Textiles are a visible 'reservoir' of Lepcha identity, but even as this reservoir draws authority through its relationship to the past, it is inextricably engaged with the present, as it always has been.

Lepcha textiles act as a mirror of present Lepcha culture, with its engagements in the contemporary world, but also as a conceptual time-machine that can visually transport one through Lepcha history, therefore displaying Lepcha history when it otherwise may be obscured or overwritten through some acts of cultural interaction. Identity, continuously forming, is woven through the Lepcha lens onto their textiles. These textiles, as 'traditions,' mark the Lepchas' engagement with their conditions throughout history and an interaction between the past and the present, a concept described by Asad (2009). This tether between the past and the present, most significantly seen in the case of nettle textiles, is powerfully symbolically deployed or embodied by Lepcha textiles as a visible emblem of Lepcha cultural identity amongst others and their belonging in their homeland. 


\section{Endnotes}

1. Lepchas call themselves Rong (or Mutanchi Rong/ Rongkup). Lepcha is used primarily by outsiders of the community (though the Rong also refer to themselves as Lepchas and sometimes use Lepcha as their surnames today) and reportedly derives from a Nepali word that roughly means "nonsense talkers" (Gorer [1938]2014: 35). Lepcha will nevertheless be the term used in this paper because it is commonly used in references to the Rong in literature and discussions.

2. Lepcha oral history related to their textiles has been documented by representatives of the Lepcha tribe. This documentation was provided generously to the authors by the Lepcha tribe in Gangtok and other parts of Sikkim, who also supplied oral history and insight into Lepcha culture via interviews with informed consent in 2018. The authors gathered additional information about the textiles at the Directorate of Handicrafts and Handloom's museum and workshop in Gangtok, Sikkim. Continual contact has been maintained with these Lepcha representatives from 2018 to now in order to track changes and inform analysis throughout the process of writing this article.

3. Anok thyaak-tuk were probably developed after the seventeenth century. Lepchas were wearing 'Tibetan' birettas decorated with coral beads-likely an early form of anok thyaak-tuk-by the twentieth century (Gorer [1938]2014: 53). Additionally, similar hats with velvet sides were worn by Qing-dynasty Chinese bureaucrats during the winter. There is clearly a history of cultural exchange embodied in these caps, but determining anok thyaak-tuk's exact roots, however, is difficult because the Lepchas have made it their own tradition by unifying its design with Lepcha mythohistory. It is thus considered a historically-rooted textile by the Lepchas. The central knot is customarily composed of nine different knots, each intended to represent one of the original Lepcha sub-clans. As there were ten sub-clans according to Lepcha oral history, the anok thyaak-tuk's wearer fulfills the role of the tenth sub-clan's representative while wearing the cap. Like these other 'Lepcha hats,' anok thyaak-tuk are sometimes adorned with feathers-an indicator of the Lepchas' relationship with their environs-and worn almost exclusively by men.

\section{References}

Appadurai, Arjun. 1988. The Social Life of Things. Cambridge: Cambridge University Press.

Asad, Talal. 2009. "The Idea of an Anthropology of Islam." Qui Parle 17(2): 1-30.
Bhabha, Homi K. 1985. "Signs Taken for Wonders: Questions of Ambivalence and Authority under a Tree Outside Delhi, May 1817." Critical Inquiry 12 (1): 144-165.

Bentley, Jenny. 2007. “'Vanishing Lepcha': Change and Cultural Revival in a Mountain Community of Sikkim." Bulletin of Tibetology 43(1-2): 59-79.

Bhasin, Veena. 2011. "Settlements and Land-Use Patterns in the Lepcha Reserve-Dzongu Zone in the Sikkim Himalaya, India." Journal of Biodiversity 2(1): 41-66.

Chakrabarti, Anjan. 2012. "Migration and Marginalisation in the 'Himalayan Kingdom' of Sikkim." Journal of Exclusion Studies 2 (1): 1-6. https://www.academia.edu/10098401/ Migration_and_Marginalisation_in_the_Himalyan_ Kingdom_of_Sikkim (accessed 17 September 2018).

Choedon, Yeshe. 1995. "Cultural Evolution of Sikkim: A Survey." Bulletin of Tibetology, Seminar Volume 1995: 73-77.

Choudhury, Maitreyee. 2006. Sikkim: Geographical Perspectives. New Delhi, Dehli: Mittal Publications.

Das, Tapan Kumar. 2009. Political Process in a Tribal Community a Study of Lepcha Political Behaviour. Ph.D. diss., University of Calcutta. http://hdl.handle. net/10603/154673 (accessed 25 September 2018).

Directorate of Handicrafts and Handloom, Government of Sikkim. 2016. Achievements. DHH-Govt. of Sikkim. http:// sikkimcrafts.gov.in/achievements.html (accessed 6 November 2018).

_. 2012. "Home." DHH-Govt. of Sikkim. http:// sikkimcrafts.gov.in/index.html (accessed on 06 November 2018).

Finley, John H., William Peterson and George Sandeman, eds. 1913. "Sikkim." In Nelson's Perpetual Loose-Leaf Encyclopcedia: An International Work of Reference, 215. 7th ed. Vol. 11. New York: Thomas Nelson \& Sons.

Foning, Arthur. 1987. Lepcha, My Vanishing Tribe. New Delhi, Dehli: Sterling Publications.

Graburn, Nelson. 2001. "What is Tradition?" Museum Anthropology 24(2/3): 6-11

Gorer, Geoffrey. [1938]2014. The Lepchas of Sikkim. New Delhi, Dehli: Gyan Publishing House.

Government of India, Ministry of Home Affairs, Office of the Registrar General \& Census Commissioner. 2001. "Data Highlights: The Scheduled Tribes Census of India 2001.” Tables on Individual Scheduled Castes (SC) and Scheduled Tribes (ST). http://censusindia.gov.in/Tables_Published/SCST/ scst_main.html (accessed 8 October 2018). 
Gurung, Manisha. 2017. "Social Transformation in Sikkim: Nomadism to Settled Agriculture.” MPhil diss., Sikkim University. http://14.139.206.50:8080/jspui/handle/1/5468 (accessed 27 September 2018).

Horner, Alice E. 1990. "The Assumption of Tradition: Creating, Collecting, and Conserving Cultural Artifacts in the Cameroon Grassfields (West Africa)." Ph.D. diss., University of California, Berkeley.

Keshav, Gautam. 2017. "Society and Economy of Sikkim Under Namgyal Rulers." PhD diss., Gauhati University. http://hdl.handle.net/10603/64249 (accessed 27 September 2018).

Lepcha, Samuel. 2016. "Philosophy of Religion in Lepcha Naamtho Naamthar-s: A Critical and Hermeneutical Enquiry." PhD diss., University of Madras. http://hdl. handle.net/10603/186235 (accessed 27 September 2018).

Lepcha, Tom Tshering, and Tar Tshering Lepcha. Indigenous Lepcha Weave. Gangtok, Sikkim, India.

Mullard, Saul. 2011. Opening of the Hidden Land: State Formation and the Construction of Sikkimese History. Leiden: Brill.

Palace Archives of Sikkim. 1905-1910. Wool Trade with Tibet. https://eap.bl.uk/archive-file/EAP880-1-2-30 (accessed 20 July 2021).

Pradhan, Bharat K. and Hemant K. Badola. 2008. "Ethnomedicinal Plant Use by Lepcha Tribe of Dzongu Valley, Bordering Khangchendzonga Biosphere Reserve, in North Sikkim, India." Journal of Ethnobiology and Ethnomedicine 4(22): 1-18. https://ethnobiomed. biomedcentral.com/articles/10.1186/1746-4269-4-22 (accessed 25 September 2018).
Rastogi, Deepali and Nupur Srivastava. 2018. "Nettle Fiber: Himalayan Wonder with Extraordinary Textile Properties." International Journal of Home Science 4(1): 281-285.

Ranger, Terence O. and Hobsbawm, Eric J. 1983. The Invention of Tradition. Cambridge; New York: Cambridge University Press.

Sarkar, Jagatpati. 1995. "A Focus on the Cultural Aspects of Sikkim.” Bulletin of Tibetology 31(1): 69-72.

Shulka, Satyendra R. 1976. Sikkim: The Story of Integration. New Delhi, Dehli: S. Chand \& Co. Pvt. Ltd.

Singh, G. P. 2008. Researches into the History and Civilization of the Kirātas. New Delhi, Dehli: Gyan Publishing House.

Subba, Jash Raj. 2008a. The Evolution of Man and the Modern Society in Mountainous Sikkim. New Dehli, Dehli: Gyan Publishing House.

2008b. History, Culture and Customs of Sikkim. New Delhi, Dehli: Gyan Publishing House.

2009. Mythology of the People of Sikkim. New Delhi, Dehli: Gyan Publishing House.

Subba, Tanka Bahadur. 1985. "The Lepchas: From Legends to the Present Day.” Religion and Society 32(2): 61-70.

Vandenhelsken, Mélanie. 2021. “Ancestrality, Migration, Rights and Exclusion: Citizenship in the Indian State of Sikkim." Asian Ethnicity 22(2): 213-234.

Wardle, Thomas. 1886. Colonial and Indian Exhibition, 1886: Official Catalogue. London: W. Clowes.

Zein-Elabdin, E. 2009. “Economics, Postcolonial Theory and the Problem of Culture: Institutional Analysis and Hybridity." Cambridge Journal of Economics 33(6): 1153-1167. 